\title{
LUMBOSACRAL TRANSITIONAL VERTEBRAE IN PATIENTS ATTENDING A TERTIARY CARE HOSPITAL OF NEPAL
}

\author{
Sanzida Khatun ${ }^{1 *}$, Diwakar Kumar Shah ${ }^{2}$
}

\begin{abstract}
Affiliation
1. Assistant Professor, Department of Anatomy, Nobel Medical College and Teaching Hospital, Nepal

2. Assistant Professor, Department of Anatomy, Nobel Medical College and Teaching Hospital, Nepal
\end{abstract}

\section{ARTICLE INFO}

Received : 18 May, 2021

Accepted : 21 July, 2021

Published：04 November 2021

(C) Authors retain copyright and grant the journal right of first publication with the work simultaneously licensed under Creative Commons Attribution License CC - BY 4.0 that allows others to share the work with an acknowledgment of the work's authorship and initial publication in this journal.

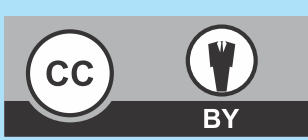

ORA 260

DOI: https://doi.org/10.3126/bjhs.v6i2.40336

* Corresponding Author

Dr. Sanzida Khatun

Assistant Professor

Department of Anatomy

Nobel Medical College and Teaching Hospital, Nepal

Email: ksanzida12@gmail.com

ORCID: https://orcid.org/0000-0002-0037-0509

\section{Citation}

Sanzida Khatun, Diwakar Kumar Shah. Lumbosacral Transitional Vertebrae in patients attending a Tertiary Care Hospital of Nepal. BJHS 2021;6(2)15. 1507-1511.

\section{ABSTRACT}

\section{Introduction}

Lumbosacral Transitional vertebrae are congenital anomalies of lumbosacral vertebral junction. It may present either as sacralization of fifth lumbar vertebrae or lumbarization of first sacral vertebrae. Various secondary pathological spinal conditions such as intervertebral disc herniation and/or degeneration, facet joint arthrosis and spinal canal or foraminal stenosis are associated with the presence of lumbosacral transitional vertebrae. The failure in the identification may lead to clinical consequences such as errors in diagnosis of disease and lumbosacral procedures.

\section{Objective}

The aim of this study was to determine the prevalence and patterns of LSTV in patients presenting to Department of Radiology of Nobel Medical College Teaching Hospital, Nepal.

\section{Methodology}

A descriptive cross-sectional study was conducted in Department of Radiology of Nobel Medical College Teaching Hospital, Nepal. Plain radiographs including Anteroposterior (AP) and Lateral views of lumbosacral spine of 343 patients referred for the scan were analyzed for the presence of lumbosacral vertebrae.

\section{Result}

Out of 343 patients, LSTV was found in 61 (17.8\%) subjects. Thirty-eight subjects (11.1\%) exhibited sacralization and 23 $(6.7 \%)$ showed lumbarization. Out of total LSTV subjects, type I A was present in 8 (13.1\%), type I B in 21 (34.4\%), type II A in 10 (16.4\%), type II B in 5 (8.2\%), type III A in 6 (9.8\%), type III B in 9 (14.8\%) and type IV in 2 (3.3\%).

\section{Conclusion}

The lumbosacral transitional vertebrae is prevalent in almost one-fifth of subjects presenting to department of radiology of Nobel Medical College and Teaching Hospital, Biratnagar for lumbosacral scan. Sacralization occurs more frequently than lumbarization, both of which alter the morphology of anatomical structures in spine. The presence of anomaly in this region may be related to occurrence of various pathological and clinical conditions.

\section{KEYWORDS}

Lumbar vertebrae, sacrum, spine, transitional vertebrae 


\section{INTRODUCTION}

Lumbosacral Transitional vertebrae (LSTV) are congenital anomalies of lumbosacral vertebral junction. It may present either as sacralization of fifth lumbar vertebrae (L5) or lumbarization of first sacral vertebrae (S1). Sacralization of L5 vertebra involves broadened and elongated transverse process of $L 5$ to its partial or complete fusion with the sacrum. Lumbarization of S1 involves partial or complete separation of S1 vertebra from remaining of the sacrum. ${ }^{1}$ The identification of LSTV can be done on all imaging modalities, but they are supposedly best imaged on Ferguson radiographs (AP radiographs angled cranially at $\left.30^{\circ}\right) .^{2}$

The vertebral column supports the weight of the upper part of human body. There is axial transmission of increased magnitude of vertical compressive forces to lumbosacral joint; the force is extended to lower limbs through sacrum and its ligaments. ${ }^{3}$ But when anomaly of L5-S1 region occurs, the iliolumbar ligaments are the sole mechanism resisting the load. ${ }^{4}$ Thus, various secondary pathological spinal conditions such as intervertebral disc herniation and/or degeneration, facet joint arthrosis and spinal canal or foraminal stenosis are associated with the presence of LSTV. $^{5}$ The failure in the identification may lead to clinical consequences such as errors in diagnosis of disease and lumbosacral procedures. ${ }^{2}$ Knowledge regarding variation in anatomy of lumbosacral vertebrae and its pathology is important in reaching a diagnosis, planning treatment and improving prognosis of various lumbosacral conditions and diseases. There are very few studies done to estimate the occurrence rate of LSTV in Nepal. This study shall add to the knowledge of prevalence and patterns of LSTV in population of eastern region of Nepal as patients from number of places from eastern region of Nepal present to this Hospital. The aim of this study was to determine the prevalence and patterns of LSTV in patients presenting to Department of Radiology of Nobel Medical College Teaching Hospital, Nepal.

\section{METHODOLOGY}

A descriptive cross-sectional study was conducted in Department of Radiology of Nobel Medical College Teaching Hospital, Nepal. The study period was from May 1, 2020 to April 30, 2021. The ethical approval was taken from IRC-NMCTH of the institution. The informed consent was signed by the participants. Plain radiographs including Antero-posterior (AP) and Lateral views of lumbosacral spine of patients referred for the scan for various reasons such as low back pain, injury, monitoring diseases such as osteoporosis and osteoarthritis were analyzed. The patients of all age groups were included in the study. The patients who had deformity or spinal surgery of lumbosacral area and radiographs with poor image quality were excluded from the study.

The study was done in 343 subjects. Simple random sampling was done.

In the plain radiographs of lumbosacral spine, the $12^{\text {th }}$ thoracic vertebrae (T12) where the ribs were attached were identified. The vertebra immediately below this vertebra was designated as first lumbar vertebra (L1). The presence or absence of LSTV was noted by counting down till L5-S1 region craniocaudally. Among the ones which had presence of LSTV, the pattern was further classified based on Castellvi classification as follows. ${ }^{7}$

Type I: Dysplastic and enlarged transverse process measuring $\geq 19 \mathrm{~mm}$ : $A$, unilateral; $B$, bilateral.

Type II: Enlarged transverse process with pseudoarticulation with sacrum: $A$, unilateral; $B$, bilateral.

Type III: Complete fusion of transverse process with sacrum: $A$, unilateral; B, bilateral.

Type IV: Mixed type with type II on one side and Type III on other side.

The data was entered and analyzed using Statistical Package for Social Sciences 16.0 software. The frequencies, percentages, mean and standard deviation was derived by descriptive analysis.

\section{RESULT}

In this study, the radiographs of 343 patients were observed. There were 117 (34.1\%) male and 226 (65.9\%) female patients. The age of the patients ranged from 6 years to 86 years with a mean of $47 \pm 16$ years.

Out of 343 patients, LSTV was found in 61 (17.8\%) subjects. The prevalence of LSTV didn't vary much in males and females; LSTV was found in 22 (18.8\%) of total (117) males and $39(17.2 \%)$ of total (226) females. Thirty-eight subjects (11.1\%) exhibited sacralization and 23 (6.7\%) showed lumbarization. Among the male patients, 19 (16.2\%) had sacralization, whereas, $3(2.6 \%)$ had lumbarization. However, among the female patients, lumbarization was seen in 20 (8.8\%) subjects which was more common than in males and sacralization was present in 19 (8.4\%) subjects.

According to Castellvi classification, among the 61 subjects with LSTV, type I was the most common type of LSTV which was present in 29 (47.5\%) participants. Type II and type III was equally frequent and type IV was the least frequently occurring type.

Out of most commonly occurring type I LSTV, type I A (unilateral type I LSTV) was present in $8(13.1 \%)$ and type I B (bilateral type I LSTV) was present in 21 (34.4\%) of total LSTV subjects. Type II A was found in 10 (16.4\%), type II B in 5 (8.2\%) , type III A in $6(9.8 \%)$, type III B in 9 (14.8\%) and type IV in 2 (3.3\%) of total LSTV subjects. Table 2 displays genderwise distribution of different types of LSTV according to Castellvi classification. Both in males and females, the most common type of LSTV was type I. In both the genders, type I B was more common that type I A. Type IV LSTV was least frequent among females and absent in males.

Table 3 displays distribution of different types of LSTV in sacralization and lumbarization. Among the sacralized LSTV, type I was found in 15 (39.5\%) subjects which was the most prevalent type and type IV was found in only 1 (2.6\%) subject. Similarly, among the lumbarized LSTV, type I was found in 14 (60.9\%) subjects all of which represented 
bilateral type (type I B) and type IV was least prevalent which was found only in 1 (4.3\%) subject. Pearson's chi-square test was done to see the relation between types of LSTV and sacralization or lumbarization in which statistically significant difference was observed ( $p$ value $=0.013$ ).

Table 1: Gender wise distribution of sacralization and
lumbarization.
\begin{tabular}{|l|r|r|r|}
\hline & $\begin{array}{c}\text { Male } \\
\text { N (\%) }\end{array}$ & $\begin{array}{c}\text { Female } \\
\text { N (\%) }\end{array}$ & $\begin{array}{c}\text { Total subjects } \\
\text { N }(\%)\end{array}$ \\
\hline Without LSTV & $95(81.2 \%)$ & $187(82.7 \%)$ & $282(82.2 \%)$ \\
\hline Sacralization & $19(16.2 \%)$ & $19(8.4 \%)$ & $38(11.1 \%)$ \\
\hline Lumbarization & $3(2.6 \%)$ & $20(8.8 \%)$ & $23(6.7 \%)$ \\
\hline Total LSTV & $22(18.8 \%)$ & $39(17.2 \%)$ & $61(17.8 \%)$ \\
\hline
\end{tabular}

Table 2: Gender-wise distribution of LSTV according to Castellvi classification.

\begin{tabular}{|l|r|r|r|}
\hline & \multicolumn{1}{|c|}{$\begin{array}{c}\text { Male } \\
\text { N (\%) }\end{array}$} & \multicolumn{1}{c|}{$\begin{array}{c}\text { Female } \\
\text { N (\%) }\end{array}$} & \multicolumn{1}{c|}{$\begin{array}{c}\text { Total } \\
\text { N (\%) }\end{array}$} \\
\hline Without LSTV & $95(81.2 \%)$ & $187(82.7 \%)$ & $282(82.2 \%)$ \\
\hline I A & $4(3.4 \%)$ & $4(1.8 \%)$ & $8(2.3 \%)$ \\
\hline I B & $9(7.7 \%)$ & $12(5.3 \%)$ & $21(6.1 \%)$ \\
\hline II A & $5(4.3 \%)$ & $5(2.2 \%)$ & $10(2.9 \%)$ \\
\hline II B & $2(1.7 \%)$ & $3(1.3 \%)$ & $5(1.5 \%)$ \\
\hline III A & $0(0 \%)$ & $6(2.7 \%)$ & $6(1.7 \%)$ \\
\hline III B & $2(1.7 \%)$ & $7(3.1 \%)$ & $9(2.6 \%)$ \\
\hline IV & $0(0 \%)$ & $2(0.9 \%)$ & $2(0.6 \%)$ \\
\hline
\end{tabular}

Table 3: Distribution of types of LSTV in Sacralization and Lumbarization.

\begin{tabular}{|c|c|c|c|c|}
\hline & $\begin{array}{c}\text { Sacralization } \\
\mathrm{N}(\%)\end{array}$ & $\begin{array}{c}\text { Lumbarization } \\
\mathbf{N}(\%)\end{array}$ & $\begin{array}{l}\text { Total } \\
\text { N (\%) }\end{array}$ & $P$ value \\
\hline IA & 8 (21.1\%) & $0(0.0 \%)$ & 8 (13.1\%) & \multirow{7}{*}{0.013} \\
\hline IB & $7(18.4 \%)$ & $14(60.9 \%)$ & $21(34.4 \%)$ & \\
\hline IIA & 7 (18.4\%) & $3(13.0 \%)$ & $10(16.4 \%)$ & \\
\hline II B & $4(10.5 \%)$ & $1(4.3 \%)$ & $5(8.2 \%)$ & \\
\hline III A & $3(7.9 \%)$ & $3(13.0 \%)$ & $6(9.8 \%)$ & \\
\hline III B & $8(21.1 \%)$ & $1(4.3 \%)$ & 9 (14.8\%) & \\
\hline IV & $1(2.6 \%)$ & $1(4.3 \%)$ & $2(3.3 \%)$ & \\
\hline
\end{tabular}

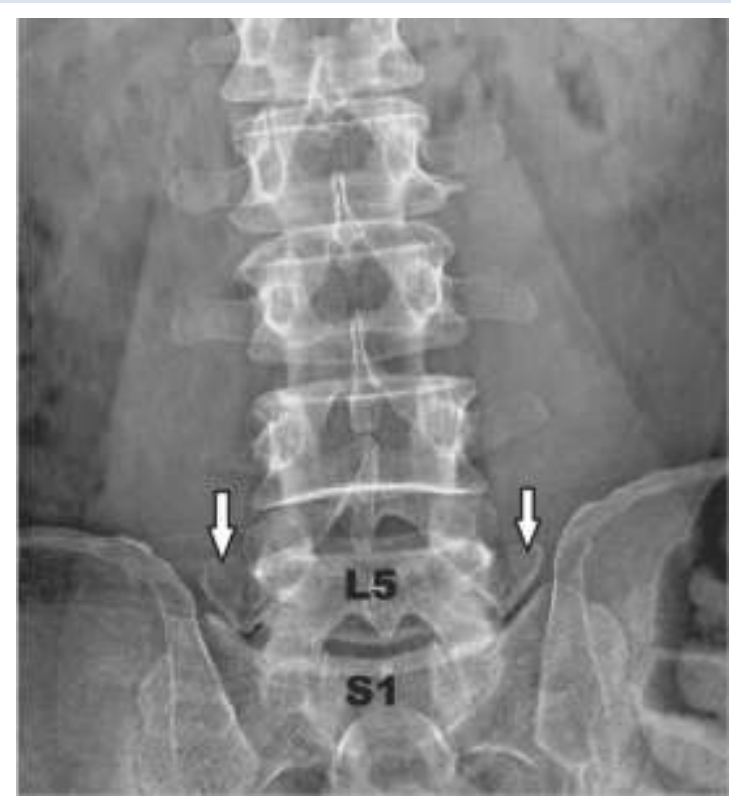

Figure 1: Radiograph showing Type 1 LSTV (Dysplastic and enlarged transverse process measuring $\geq 19 \mathrm{~mm}$ )

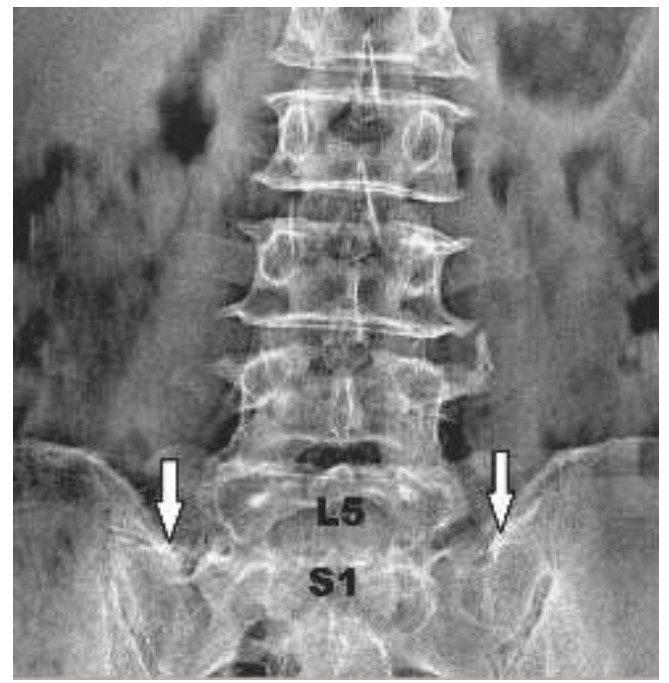

Figure 2: Radiograph showing Type II LSTV (Type II: Enlarged transverse process with pseudo-articulation with sacrum).

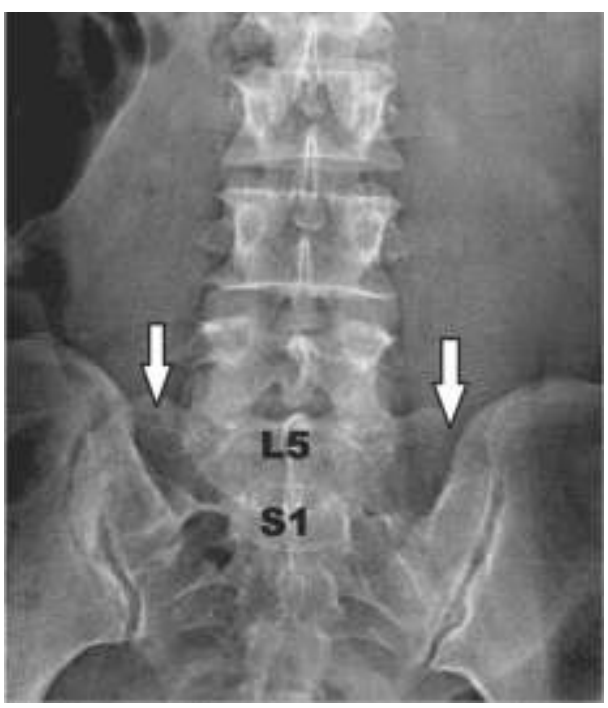

Figure 3: Radiograph showing Type III LSTV (Complete fusion of transverse process with sacrum).

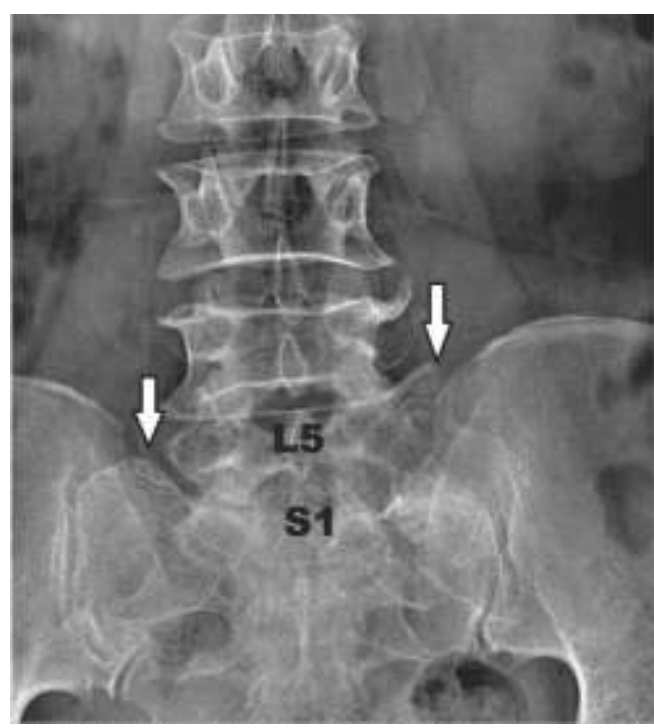

Figure 4: Radiograph showing Type IV LSTV (pseudoarticulation on right and complete fusion of transverse process with sacrum on left side).

\begin{tabular}{l|ll}
1509 & Birat Journal of Health Sciences & ISSN: 2542-2758 (Print) 2542-2804 (Online) \\
\cline { 2 - 4 } & Vol.6/No.2/Issue 15/May-Aug., 2021 & (n)
\end{tabular}




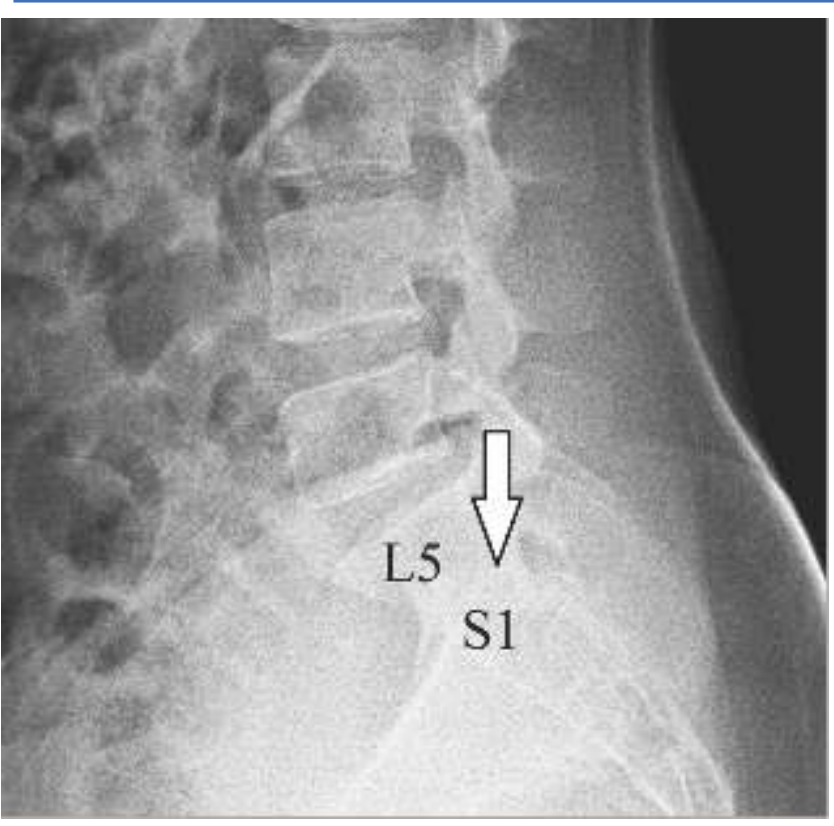

Figure 5: : Radiograph showing lateral view of complete fusion of sacralized LSTV

\section{DISCUSSION}

Variations in the lumbosacral region of the spine are fairly common. LSTV is a commonly encountered anomaly in lumbosacral region. The present study reports the prevalence of LSTV and its pattern in population of eastern Nepal. In this study, LSTV was found in almost one-fifth of the subjects. Sacralization was more common than lumbarization. In females, however, the frequency of sacralization and lumbarization was almost equal.

It has been documented that the prevalence of LSTV varies worldwide. In this study, LSTV was found in 61 (17.8\%) subjects out of 343 patients. Similar to this finding, the prevalence of LSTV in various studies has been reported to be about $10 \%$ to $20 \%{ }^{1,6,8-17}$ In contrast to these findings, higher prevalence of LSTV ranging from $23 \%$ to $36 \%$ have been reported by Lee et al, Dai et al, Delport et al, Luoma et al, Erken et al and Apazidis et al in their studies. ${ }^{18-23}$ In other studies, however, lower prevalence rates of below $10 \%$ have been reported by Kim et al, Tini et al Khashoggi et al and Chithriki et al. ${ }^{24-27}$ In this study, 38 (11.1\%) subjects exhibited sacralization and $23(6.7 \%)$ showed lumbarization. In consistence with these findings, many studies have reported higher frequency of sacralization in comparison to lumbarization. The prevalence of sacralization and lumbarization demonstrated by French et al was 5.8\% and $4.1 \%$, Hughes et al was $9.2 \%$ and $4.2 \%$, Steinberg et al was $14.0 \%$ and $4.3 \%$, Santiago et al was $11.6 \%$ and $7.2 \%$, Hald et al was $7.8 \%$ and $5.9 \%$, Hahn et al was $7.5 \%$ and $4.5 \%$, Lee et al was $13.9 \%$ and $9.9 \%$, Khashoggi et al was $7.36 \%$ and $0.02 \%$ and Chithriki et al was 5.0\% and 3.4\%, respectively. ${ }^{1,8-10,12,13,1826,27}$ In few studies, however, lower frequency of sacralization in comparison with lumbarization has been demonstrated. ${ }^{11,14,24}$ Paik et al reported equal prevalences of $5.3 \%$ each of sacralization and lumbarization in their study. ${ }^{15}$

When classified according to Castellvi classification, the most common type of LSTV observed was Type I. Bilateral type I (type I B) LSTV was more common than unilateral type I (type I A) LSTV. The finding in this study that type I LSTV is most prevalent is consistent with the findings of most of the authors. ${ }^{6,23,26}$ However, the data differs from the findings of Bhattarai and Apazidis which showed more frequent type I A than type I B. ${ }^{6,23}$ Khashoggi et al demonstrated that type I B LSTVwas more common than type I A LSTV which is similar to the finding of this study. ${ }^{26}$

The presence of anomaly in this region may be related to occurrence of various pathological and clinical conditions as this is a significant load bearing area of the body. ${ }^{3,5}$ They are usually the result of altered morphology of joints and facets. ${ }^{28}$ The association of LSTV and lower back pain has been well documented in various studies. ${ }^{2,5,16,19,28,29}$ Castellvi type II and IV type of LSTV, particularly, have been frequently associated with lower back pain resulting due to pseudoarticulation susceptible to osteophytes formation. ${ }^{16,29}$ More degenerative lumbar disc above LSTV than between LSTV and sacrum in findings in MRI have been documented in various studies. 50

Spinal surgeries at incorrect levels have been reported in LSTV due to errors in numeric identification of the vertebrae. This may result in second surgery which may be detrimental to the patient and hospital in terms of cost, disease and post-operative complications. It is imperative that the spinal surgeons suggest review of plain radiographs along with the MRI to be aware of LSTV to reduce surgical and procedural errors. ${ }^{2,23}$ Furthermore, a study demonstrated that the presence of LSTV limits the clinical improvement after microdisectomy for lumbar disc herniation. ${ }^{31}$ The patient and the clinician should also be prepared for clinical discrepancies in cases of anomaly.

\section{LIMITATIONS OF THE STUDY}

This study doesn't represent the prevalence of larger population as it was a hospital based study. Furthermore, the imaging of the patients presenting to hospital for some underlying factor were analysed which doesn't represent the entire healthy and asymptomatic population. Error might have occurred due to presence of extra lumbar rib. The presence of extra lumbar rib could not be confirmed as chest radiograph of same patient was not assessed.

\section{RECOMMENDATIONS}

Additional research with multiple institution based studies including healthy control group will be required to assess occurrence of LSTV and its association with various clinical conditions. The radiographs of complete trunk of the same participant should be assessed to accurately count the vertebrae and the ribs. Multiple observers to minimize the diagnostic error can be implemented.

\section{CONCLUSION}

The LSTV is prevalent in almost one-fifth of subjects presenting to department of radiology of Nobel Medical College and Teaching Hospital, Biratnagar for lumbosacral scan. Sacralization occurs more frequently than 
lumbarization, both of which alter the morphology of anatomical structures in spine. The presence of anomaly in this region may be related to occurrence of various pathological and clinical conditions. It is imperative that the spinal surgeons and clinicians review plain radiographs along with the MRI to be aware of LSTV to reduce surgical and procedural errors.

\section{ACKNOWLEDGEMENTS}

We acknowledge the support from Department of
Radiology, Nobel Medical College for coordinating during data collection for the study.

\section{CONFLICTS OF INTEREST}

We declare no conflict of interest in this work.

\section{FINANCIAL DISCLOSURE}

None

17. Carrino JA, Campbell Jr PD, Lin DC, Morrison WB, Schweitzer ME, Flanders $A E$, Eng J, Vaccaro AR. Effect of spinal segment variants on numbering vertebral levels at lumbar MR imaging. Radiology. 2011 Apr;259(1):196-202. DOI: https://doi.org/10.1148/radiol.11081511

18. Lee CH, Park CM, Kim KA, Hong SJ, Seol HY, Kim BH, Kim JH. Identification and prediction of transitional vertebrae on imaging studies: anatomical significance of paraspinal structures. Clinical Anatomy. 2007 Nov;20(8):905-14. DOI: https://doi.org/10.1002/ca.20540

19. Dai L. Lumbosacral transitional vertebrae and low back pain. Bulletin (Hospital for Joint Diseases (New York, NY)). 1999 Jan 1;58(4):191-3. PMID: 10711367

20. Delport EG, Cucuzzella TR, Kim N, Marley J, Pruitt C, Delport AG. Lumbosacral transitional vertebrae: incidence in a consecutive patient series. Pain physician. 2006 Jan 1;9(1):53. PMID: 16700281

21. Luoma K, Vehmas T, Raininko R, Luukkonen R, Riihimäki H. Lumbosacral transitional vertebra: relation to disc degeneration and low back pain. Spine. 2004 Jan 15;29(2):200-5. DOI: 10.1097/01. BRS.0000107223.02346.A8

22. Erken E, Ozer HT, Gulek B, Durgun B. The association between cervical rib and sacralization. Spine. 2002 Aug 1;27(15):1659-64. DOI: 10.1097/00007632-200208010-00013

23. Apazidis A, Ricart PA, Diefenbach CM, Spivak JM. The prevalence of transitional vertebrae in the lumbar spine. The Spine Journal. 2011 Sep 1;11(9):858-62. DOI: 10.1016/j.spinee.2011.08.005

24. Kim NH, Suk KS. The role of transitional vertebrae in spondylolysis and spondylolyticspondylolisthesis. Bulletin (Hospital for Joint Diseases (New York, NY)). 1997 Jan 1;56(3):161-6. PMID: 9361917

25. Tini PG, Wieser C, Zinn WM. The transitional vertebra of the lumbosacral spine: its radiological classification, incidence, prevalence, and clinical significance. Rheumatology. 1977 Aug 1;16(3):180-5. DOI: 10.1093/rheumatology/16.3.180

26. Khashoggi KG, Hafiz RM, Bock YM, Kaki AM. Determination of lumbosacral transitional vertebrae in kidney urinary bladder $\mathrm{x}$-ray films in the Saudi population. Saudi medical journal. 2017 Aug;38(8):794. DOI: 10.15537/smj.2017.8.19341

27. Chithriki M, Jaibaji M, Steele R. The anatomical relationship of the aortic bifurcation to the lumbar vertebrae: a MRI study. Surgical and Radiologic Anatomy. 2002 Dec;24(5):308-12. DOI: 10.1007/s00276-002-0036-3

28. Mahato NK. Facet dimensions, orientation, and symmetry at L5-S1 junction in lumbosacral transitional states. Spine. $2011 \mathrm{Apr}$ 20;36(9):E569-73. DOI: 10.1097/BRS.0b013e3181f6ecb2

29. Jancuska JM, Spivak JM, Bendo JA. A review of symptomatic lumbosacral transitional vertebrae: Bertolotti's syndrome. International journal of spine surgery. 2015 Jan 1;9. DOI: 10.14444/2042

30. Aihara T, Takahashi K, Ogasawara A, Itadera E, Ono Y, Moriya H. Intervertebral disc degeneration associated with lumbosacral transitional vertebrae: a clinical and anatomical study. The Journal of bone and joint surgery. British volume. 2005 May;87(5):687-91. DOI: 10.1302/0301-620X.87B5.15727

31. Ahn SS, Chin DK, Kim SH, Kim DW, Lee BH, Ku MG. The clinical significance of lumbosacral transitional vertebrae on the surgical outcomes of lumbar discectomy: a retrospective cohort study of young adults. World neurosurgery. 2017 Mar 1;99:745-50. DOI: 10.1016/j.wneu.2016.05.073
16. Tang M, Yang XF, Yang SW, Han P, Ma YM, Yu H, Zhu B. Lumbosacral transitional vertebra in a population-based study of 5860 individuals: prevalence and relationship to low back pain. European journal of radiology. 2014Sep 1;83(9):1679-82. DOI:10.1016/j.ejrad.2014.05.036 